\section{Greetings from the editor 2021}

\author{
Josef S Smolen (1)
}

The year just past, 2020, will be remembered as the year COVID-19, elicited by SARS-CoV-2, was recognised as a pandemic, with about 120000 reported cases and 4000 deaths globally around the ides of March. ${ }^{1}$ Since then, a huge burden of morbidity and especially mortality has accrued, soon to exceed 65 million infected persons and 1.5 million deaths worldwide. $^{2}$ Numerous challenges have arisen, including inconsistent, frequently unpredictable and often indifferent, even frivolous approaches of politicians to the problem and varying attitudes espoused by leading experts in epidemiology and/or infectious diseases (eg, 'masks don't help' vs 'masks are very important'; or 'aim for herd immunity' vs 'herd immunity will not occur without a vaccine'; or 'lockdown is a must' vs 'no lockdown needed'). Together this has been confusing, distressing and worrisome in light of overflowing intensive care units and mass funerals in many regions of the world.

As these greetings were being written, the first vaccine, an mRNA vaccine currently named BNT162b2, has been announced effective and safe, developed by a German company, BioNtech, tested in a trial performed by a US company, Pfizer, ${ }^{3}$ and using lipid nanoparticles for vaccine delivery provided by an Austrian company, Polymun ${ }^{4}$-a great success of European and transcontinental collaboration. The efficacy and safety of more vaccines have been or are soon to be revealed.

European and global collaboration was indeed also wonderful to see among rheumatologists during these first months of the COVID-19 pandemic. International databases to register patients with COVID-19 with rheumatic and musculoskeletal diseases (RMDs) were established and first analyses presented rapidly to assist clinical practice, ${ }^{5}$ as were preliminary recommendations regarding the management of patients with RMDs during the pandemic. ${ }^{6-9}$

Rheumatology, Medical University of Vienna, Vienna A-1090, Austria

Correspondence to Professor Josef S Smolen, Division of Rheumatology, Department of Medicine 3, Medical University of Vienna, Vienna A-1090, Austria; josef.smolen.ard@meduniwien.ac.at
MANUSCRIPTS ON COVID-19 AND ARD Just like many other journals, the Annals of the Rheumatic Diseases (ARD) was overwhelmed with submissions since March 2020, when the pandemic fully hit Europe-the number of submitted manuscripts doubled over several months compared with previous years. Just like other journals, $A R D$ was confronted with the challenge to weigh the quest for the highest scientific quality, such as focusing on randomised controlled trials or requesting validation of data in independent patient cohorts, against the importance to provide our readers with rapid, first-hand information in an area where nothing was known at that time, with new information emerging weekly and sometimes daily. Indeed, publishing such information rapidly, as $A R D$ and many other renowned journals did, facilitated rapid growth of knowledge, essentially in real time with every single new publication. The first ARD paper on COVID-19 and RMDs ${ }^{10}$ appeared online less than 2 weeks after the announcement of the pandemic by WHO, and by the time other rheumatology journals started publishing on the topic, about a dozen reports were already fully typeset and available online for $A R D$ readers.

We owe sincere thanks to the referees who were willing to expedite the review process of the many submitted extended and concise reports or letters related to COVID-19—about a handful of reviewers provided their assessments within 1-3 days; thank you, thank you! And my gratitude goes also to the publisher and BMJ staff for making extraordinary efforts to bring the papers online rapidly in a printedited version-the time between acceptance and online publication was often just a few days; importantly, all COVID19-related papers have been, and continue to be, made freely accessible to the public.

I am also very grateful to the Associate Editors for their support during these times and especially for the thorough assessments offered, always balanced by mature reflection on the trade-offs mentioned above, of which the referees were fully aware. Meanwhile a broad knowledge base on COVID-19 has accumulated in medicine generally and rheumatology in particular. Consequently, such studies are no longer judged primarily by how the information base can be expanded with critical open-mindedness for the delicate situation of newly emerging data at the beginning of a pandemic, but are now required to be performed, once again, with highest scientific rigour.

When one searches 'Pubmed' for publications on COVID-19-related topics in $A R D$ during 2020, one finds almost 250 papers published either in print or online-a record number for a single subject in such a short time. About 200 of these items are correspondences and relevant responses appearing online, reflecting ARD's commitment to provide an open discussion forum concerning matters of contemporary importance, but also a genuine proof of the willingness and interest of the global $A R D$ readership to contribute to the topic by providing critical assessments, asking authors for additional data, sharing experience and expanding on previous communications-a true reflection of the attentiveness and strength of the readers to interact on issues related to this newly emerging disease of such global moment and societal impact.

The trajectories of this evolving information base are summarised in this first 2021 issue of $A R D$ by Lauper et al. ${ }^{11}$ Moreover, in the current and the subsequent 2 months, more than 9 months after the first COVID-19 publication appeared online in $A R D$, we will aggregate the online correspondences on the topic as they have evolved during the first calendar year of the pandemic so they can be easily brought into perspective by the readers.

\section{RHEUMATOLOGISTS AT THE FOREFRONT}

This pandemic was challenging for patients and rheumatologists alike. On the one hand, based on the hydroxychloroquine hype as a prophylaxis or therapy against COVID-19, further amplified by politicians but turning out to be wrong both in terms of anti-SARS-CoV-2 efficacy as well as reported major safety concerns, patients with autoimmune diseases who needed this treatment could not access it. ${ }^{12}$ Many hospitals were overwhelmed with caring for patients with COVID-19 and had to postpone regular care. As physical distancing is extremely important in preventing infection, many patients cancelled or did not even seek appointments in doctors' offices or clinics. Consequently, other means of interaction had to be developed: virtual consultations and telemedicine rapidly expanded. ${ }^{13}{ }^{14}$ However, as was also reported in $A R D$, not seeing rheumatologists face-to-face may 
bear life-threatening or organ-threatening risks. ${ }^{15} 16$

Beyond diseases of their immediate specialty, rheumatologists have conveyed their expertise in other respects during the pandemic. Rheumatologists are experts in immunology and its therapeutic sequelaehardly any specialty offers the breadth and depth of knowledge about efficacy and safety of immunomodulating therapies, including biological treatments and glucocorticoids. Rheumatologists have not only been at the forefront of developing anti-inflammatory therapies for many decades, ${ }^{17} 18$ but have also consulted for and even spearheaded trials of such therapies in patients with COVID-19, in close collaboration with pulmonologists, infectious disease specialists and epidemiologists. ${ }^{19}$ Rheumatologists are also at the forefront of COVID-19 characterisation, for example by defining new disease entities like COVID-19-related Kawasaki-mimicking disease (Kawa-COVID-19) ${ }^{20}$ or by caring for patients with a life-threatening cytokine storm. In this issue preliminary criteria for COVID-19 cytokine storm are presented, a potential milestone in coping with the disease. $^{2122}$

\section{FROM REALITY TO VIRTUALITY AND BACK}

In her ofttimes frank, honest, democratic and caring political manner, German Chancellor Angela Merkel said on the occasion of lockdown restrictions imposed to fight the pandemic in April 2020: "Diese Pandemie ist eine Zumutung für die Demokratie" - a statement full of truth and compassion; the term 'Zumutung' not easily translated confers the notion of 'imposition': 'This pandemic is an imposition on democracy'. This pandemic is also an imposition on medicine, on physicians, healthcare professionals and all involved in patient care, as it was and still is leading to despair among our colleagues in many countries. This was thoughtfully reflected in a letter on 'Hope' during the initial weeks of the pandemic, published earlier this year. ${ }^{23} 24$ Hopefully the vaccines mentioned above will be soon widely available and work well, and hopefully effective therapies will be found.

The last year can also be regarded as the 'year of virtual congresses'. Not only was the European League Against Rheumatism (EULAR) forced to move its Annual Congress from the Frankfurt location to the virtual arena, but many national European conferences and most recently the Annual Meeting of the American College of Rheumatology were held remotely. While this format may have enabled more participants to join and likely allowed everyone to be more selective in attending sessions or talks, the lack of person-toperson and group interactions is a true loss in all the senses discussed already previously. ${ }^{25}$ I wish the pandemic will move into virtual reality before the next Annual EULAR Congress!

\section{BEYOND COVID-19}

Let us now look beyond COVID-19 and its consequences. In this January 2021 issue a series of papers recently developed by various EULAR task forces are presented. These include the definition of difficult-to-treat rheumatoid arthritis, ${ }^{26}$ management of adverse events elicited by immune checkpoint inhibitors ${ }^{27}$ and prevention of fragility fractures, ${ }^{28}$ but also deal with core sets for pregnancy registries $^{29}$ and rheumatology specialty training. ${ }^{30}$ It is always enlightening to see the ambition and determination that govern these initiatives which provide important information based on evidence and expert opinion. In addition, points-toconsider when using Janus kinase inhibitor therapy are published ${ }^{31}$; of note, this paper was developed by an international task force formed across several specialties and addresses inflammatory diseases beyond the rheumatological ones.

All these papers are complemented by many original research articles on clinical and basic research efforts on rheumatological topics of major interest. And the three new sections 'Views on News', 'Heroes and Pillars of Rheumatology' and 'Thinking the Unthinkable' are all also represented this month. Please take the pleasure reading all these papers and please provide us with your feedback and suggestions.

And did you see the new appearance of $A R D$ ? Seven years after the previous design was introduced it was deemed desirable to change the cover of the journal. While always striving to bring cutting edge clinical and translational research into focus, the new cover reflects ARD's mission, with the EULAR blue brightening it up and connecting it all together. I hope that you like this new design.

All that remains now is for me to wish you a happy and healthy New Year. Please stay safe and enjoy the current and the upcoming issues of the Annals of the Rheumatic Diseases.

Funding The authors have not declared a specific grant for this research from any funding agency in the public, commercial or not-for-profit sectors.

Competing interests None declared.
Patient and public involvement Patients and/or the public were not involved in the design, or conduct, or reporting, or dissemination plans of this research.

Patient consent for publication Not required.

Provenance and peer review Commissioned; internally peer reviewed.

(c) Author(s) (or their employer(s)) 2021. No commercial re-use. See rights and permissions. Published by BMJ.

\section{(A) Check for updates}

To cite Smolen JS. Ann Rheum Dis 2021;80:1-3.

Received 30 November 2020

Accepted 30 November 2020

Ann Rheum Dis 2021;80:1-3.

doi:10.1136/annrheumdis-2020-219628

\section{ORCID iD}

Josef S Smolen http://orcid.org/0000-0002-4302-8877

\section{REFERENCES}

1 World Health Organization. WHO Director-General's opening remarks at the media briefing on COVID-19 - 11 March 2020, 2020. Available: https://www who int/director-general/speeches/detail/who-directorgeneral-s-opening-remarks-at-the-media-briefing-oncovid-19-11-march-2020

2 European Centre for Disease Prevention and Control (ECDC). COVID-19 situation update worldwide. Available: https://www.ecdc.europa.eu/en/ geographical-distribution-2019-ncov-cases; [Accessed 27 Nov 2020].

3 Pfizer and BioNTech announce vaccine candidate against COVID-19 achieved success in first interim analysis from phase 3 study, 2020. Available: https:// www pfizer com/news/press-release/press-releasedetail/pfizer-and-biontech-announce-vaccinecandidate-against

4 Pancevski B. If one leading coronavirus vaccine works, THANK this tiny firm in rural Austria. Wall Street Journal 2020 https://www.wsj.com/articles/if-oneleading-coronavirus-vaccine-works-thank-this-tinyfirm-in-rural-austria-11604664001

5 Gianfrancesco M, Hyrich KL, Al-Adely S, et al. Characteristics associated with hospitalisation for COVID-19 in people with rheumatic disease: data from the COVID-19 global rheumatology alliance physician-reported registry. Ann Rheum Dis 2020:79:859-66.

6 Landewé RBM, Machado PM, Kroon F, et al. EULAR provisional recommendations for the management of rheumatic and musculoskeletal diseases in the context of SARS-CoV-2. Ann Rheum Dis 2020;79:851-8.

7 Mikuls TR, Johnson SR, Fraenkel L, et al. American College of rheumatology guidance for the management of rheumatic disease in adult patients during the COVID-19 pandemic: version 1. Arthritis Rheumatol 2020;72:1241-51.

8 Matucci-Cerinic M, Bruni C, Allanore Y, et al. Systemic sclerosis and the COVID-19 pandemic: World Scleroderma Foundation preliminary advice for patient management. Ann Rheum Dis 2020;79:724-726

9 Schulze-Koops H, Specker C, Iking-Konert C, et al. Preliminary recommendations of the German Society of rheumatology (DGRh eV) for the management of patients with inflammatory rheumatic diseases during the SARS-CoV-2/COVID-19 pandemic. Ann Rheum Dis 2020;79:840-2

10 Figueroa-Parra G, Aguirre-Garcia GM, GamboaAlonso CM, et al. Are my patients with rheumatic diseases at higher risk of COVID-19? Ann Rheum Dis 2020;79:839-40.

11 Lauper K, Bijlsma JWJ, Burmester GR. Trajectories of COVID-19 information in the Annals of the rheumatic 
diseases: the first months of the pandemic. Ann Rheum Dis 2021;80:26-30.

12 McInnes IB. COVID-19 and rheumatology: first steps towards a different future? Ann Rheum Dis 2020;79:551-2.

13 Zhang Y, Wang J, Zhao L, et al. Online management of rheumatoid arthritis during COVID-19 pandemic. Ann Rheum Dis 2021;80:e4.

14 So H, Szeto C-C, Tam L-S. Patient acceptance of using telemedicine for follow-up of lupus nephritis in the COVID-19 outbreak. Ann Rheum Dis 2020:doi: 10.1136/annrheumdis-2020-218220. [Epub ahead of print 24 June 2020].

15 Monti S, Delvino P, Bellis E, et al. Impact of delayed diagnoses at the time of COVID-19: increased rate of preventable bilateral blindness in giant cell arteritis. Ann Rheum Dis 2020;79:1658-9.

16 Giollo A, Bixio R, Gatti D, et al. Challenge of diagnosing ANCA-associated vasculitis during COVID-19 pandemic: a missed 'window of opportunity'. Ann Rheum Dis 2020:doi: 10.1136/ annrheumdis-2020-218830. [Epub ahead of print 19 Aug 2020].

17 Elliott MJ, Maini RN, Feldmann M, et al. Randomised double-blind comparison of chimeric monoclonal antibody to tumour necrosis factor $\alpha$ (Ca2) versus placebo in rheumatoid arthritis. The Lancet 1994:344:1105-10.
18 Hench PS, Kendall EC, Slocumb CH. The effect of a hormone of the adrenal cortex (17-hydroxy-11 dehydrocorticosterone; compound $\mathrm{E}$ ) and of pituitary adrenocorticotropic hormone on rheumatoid arthritis. Proc Staff Meet Mayo Clin 1949;24:181.

19 Ramiro S, Mostard RLM, Magro-Checa C, et al. Historically controlled comparison of glucocorticoids with or without tocilizumab versus supportive care only in patients with COVID-19-associated cytokine storm syndrome: results of the chiC study. Ann Rheum Dis 2020;79:1143-51.

20 Pouletty M, Borocco C, Ouldali N, et al. Paediatric multisystem inflammatory syndrome temporally associated with SARS-CoV-2 mimicking Kawasaki disease (Kawa-COVID-19): a multicentre cohort. Ann Rheum Dis 2020;79:999-1006.

21 Caricchio R, Gallucci M, Dass C, et al. Preliminary predictive criteria for COVID-19 cytokine storm. Ann Rheum Dis 2021;80:88-95.

22 Nigrovic PA. COVID-19 cytokine storm: what is in a name? Ann Rheum Dis 2021;80:3-5.

23 Sheth K. Hope. Ann Rheum Dis 2020;79:986.

24 Pisetsky DS. Hopefulness of 'Hope'. Ann Rheum Dis 2020;79:849-50.

25 Smolen JS. Greetings from the editor 2020. Ann Rheum Dis 2020;79:677-8.
26 Nagy G, Roodenriis NM, Welsing PM, et al. EULAR definition of difficult-to-treat rheumatoid arthritis. Ann Rheum Dis 2021;80:31-5.

27 Kostine M, Finckh A, Bingham CO, et al. EULAR points to consider for the diagnosis and management of rheumatic immune-related adverse events due to cancer immunotherapy with checkpoint inhibitors. Ann Rheum Dis 2021;80:36-48.

28 Adams J, Wilson N, Hurkmans E, et al. 2019 EULAR points to consider for non-physician health professionals to prevent and manage fragility fractures in adults 50 years or older. Ann Rheum Dis 2021;80:57-64

29 Meissner Y, Fischer-Betz R, Andreoli L, et al. EULAR recommendations for a core data set for pregnancy registries in rheumatology. Ann Rheum Dis 2021:80:49-56.

30 Sivera F, Alunno A, Najm A, et al. 2019 EULAR points to consider for the assessment of competences in rheumatology specialty training. Ann Rheum Dis 2021;80:65-70.

31 Nash P, Kerschbaumer A, Dörner T, et al. Points to consider for the treatment of immune-mediated inflammatory diseases with Janus kinase inhibitors: a consensus statement. Ann Rheum Dis 2021:80:71-87. 